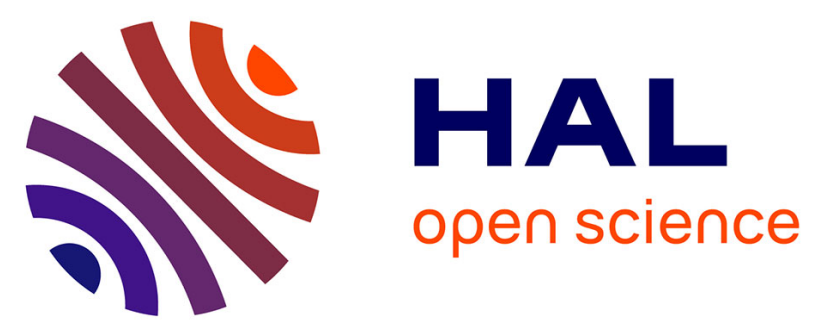

\title{
A comparative study on the pore-size and filter type effect on the molecular composition of soil and stream dissolved organic matter
}

\author{
Marie Denis, Laurent Jeanneau, Anne-Catherine Pierson-Wickmann, \\ Guillaume Humbert, Patrice Petitjean, Anne Jaffrézic, Gérard Gruau
}

\section{To cite this version:}

Marie Denis, Laurent Jeanneau, Anne-Catherine Pierson-Wickmann, Guillaume Humbert, Patrice Petitjean, et al.. A comparative study on the pore-size and filter type effect on the molecular composition of soil and stream dissolved organic matter. Organic Geochemistry, 2017, 110, pp.36-44. 10.1016/j.orggeochem.2017.05.002 . insu-01521676

\section{HAL Id: insu-01521676 \\ https://hal-insu.archives-ouvertes.fr/insu-01521676}

Submitted on 12 May 2017

HAL is a multi-disciplinary open access archive for the deposit and dissemination of scientific research documents, whether they are published or not. The documents may come from teaching and research institutions in France or abroad, or from public or private research centers.
L'archive ouverte pluridisciplinaire HAL, est destinée au dépôt et à la diffusion de documents scientifiques de niveau recherche, publiés ou non, émanant des établissements d'enseignement et de recherche français ou étrangers, des laboratoires publics ou privés. 


\section{Accepted Manuscript}

A comparative study on the pore-size and filter type effect on the molecular composition of soil and stream dissolved organic matter

Marie Denis, Laurent Jeanneau, Anne-Catherine Pierson-Wickman, Guillaume Humbert, Patrice Petitjean, Anne Jaffrézic, Gérard Gruau

PII: $\quad$ S0146-6380(17)30061-X

DOI: $\quad$ http://dx.doi.org/10.1016/j.orggeochem.2017.05.002

Reference: $\quad$ OG 3546

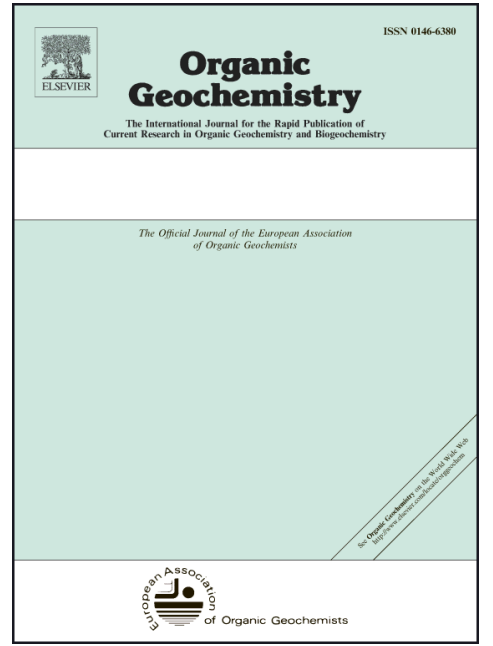

To appear in: $\quad$ Organic Geochemistry

Received Date: $\quad 31$ January 2017

Revised Date: $\quad 28$ April 2017

Accepted Date: $\quad 3$ May 2017

Please cite this article as: Denis, M., Jeanneau, L., Pierson-Wickman, A-C., Humbert, G., Petitjean, P., Jaffrézic, A., Gruau, G., A comparative study on the pore-size and filter type effect on the molecular composition of soil and stream dissolved organic matter, Organic Geochemistry (2017), doi: http://dx.doi.org/10.1016/j.orggeochem. 2017.05.002

This is a PDF file of an unedited manuscript that has been accepted for publication. As a service to our customers we are providing this early version of the manuscript. The manuscript will undergo copyediting, typesetting, and review of the resulting proof before it is published in its final form. Please note that during the production process errors may be discovered which could affect the content, and all legal disclaimers that apply to the journal pertain. 
A comparative study on the pore-size and filter type effect on the molecular composition of soil and stream dissolved organic matter

Marie Denis ${ }^{a^{*}}$, Laurent Jeanneau ${ }^{a}$, Anne-Catherine Pierson-Wickman ${ }^{\text {a }}$, Guillaume Humbert b,c , Patrice Petitjean ${ }^{a}$, Anne Jaffrézic ${ }^{\text {b,c }}$, Gérard Gruau ${ }^{\text {a }}$

a OSUR, UMR 6118 Géosciences Rennes, Université de Rennes 1 -CNRS, Rennes, France ${ }^{\mathrm{b}}$ Agrocampus Ouest, UMR 1069, Rennes, France

${ }^{\mathrm{c}}$ INRA, UMR 1069 Sol Agro et hydrosystèmes Spatialisation, Rennes, France

*Corresponding author:

Université de Rennes 1, OSUR, UMR 6118 Géosciences Rennes., Campus de Beaulieu, 263 rue du Général Leclerc, 35042 Rennes Cedex, France.

e-mail: mariedenis57@hotmail.fr 


\section{Introduction}

Dissolved organic matter (DOM) is a dynamic and important part of the carbon cycle and essential for the understanding of soil properties and functioning (Kalbitz et al., 2000). Due to its properties of complexation, DOM acts as a carrier phase, being involved in the mobility, degradation and bioavailability of micropollutants at the landscape scale (Neale et al., 2011). At the catchment scale, the main contributors to the transfer from soils to rivers are the headwater areas (Ågren et al., 2007), in which DOM comes mainly from riparian wetlands connected to streams by water tables (Morel et al., 2009). As a consequence, it is necessary to investigate both stream and soil DOM to understand transfers along the soil-river continuum. However, despite the fact that DOM has been studied for a long-time, its physical definition remains unclear.

The term "dissolved" does not refer to its chemical state since DOM is operationally defined by the filter pore-size used to isolate it from the particulate phase. This may result in concentration and compositional shifts since different filter pore-size, namely $0.2,0.45$ and $0.7 \mu \mathrm{m}$, are used in DOM studies. The filtration at $0.45 \mu \mathrm{m}$ was initially selected because it corresponds roughly to the upper limit size of viruses and the lower limit of bacteria. But However, some prokaryotes can be smaller than $0.45 \mu \mathrm{m}$ and so filtration at $0.2 \mu \mathrm{m}$ was recommended for studies where all microbiota have to be removed from samples (Krieg, 2005). However, a drawback of 0.45 and $0.2 \mu \mathrm{m}$ filters is that they are made of organic material such as cellulose acetate, which can induce contamination problems, leading a part of the DOM research community to use $0.7 \mu \mathrm{m}$ glass fibre filters. Moreover, the boundaries between particulate, colloidal and dissolved fractions remain unclear. The international union of pure and applied chemistry (IUPAC) defines colloids as "molecules or polymolecular 
particles dispersed in a medium which have at least in one direction a dimension roughly between $1 \mathrm{~nm}$ and $1 \mu \mathrm{m}$ ". As with the isolation of the dissolved phase, colloids are operationally defined, and the fraction of colloids in the dissolved fraction depends on the filter pore-size. Since colloids are complex supramolecular architectures bounded by weak forces and composed of mineral and metallic phases, natural organic matter, cations and anions (Gu et al., 1994), their occurrence in the dissolved phase may modify the concentration and the composition of DOM. Consequently, the possibility to compare results from studies using different filter pore-sizes is uncertain.

This problem has been explored by Nimptsch et al. (2014) who compared the influence of filter type and porosity on freshwater DOM composition using spectroscopic analyses. They observed a small but significant effect on chromophoric DOM composition between samples filtered with $0.7 \mu \mathrm{m}$ and $0.2 \mu \mathrm{m}$ filters and interpreted it as a filter type effect. However, this difference did not seem to be systematic. On the other hand, Zsolnay (2003) found no differences in dissolved organic carbon (DOC), UV absorption or fluorescence emission between samples from hydrosphere, soil extracts and leachates filtered at $0.4 \mu \mathrm{m}$ and $0.6 \mu \mathrm{m}$. Gandois et al. (2010) also compared concentration and UV spectroscopic data for throughfall samples filtered at $1.2 \mu \mathrm{m}$ and $0.2 \mu \mathrm{m}$ and found no significant differences.

Sanderman et al. (2008) compared samples filtered at $0.7 \mu \mathrm{m}$ and $0.45 \mu \mathrm{m}$, and found no differences for DOC concentration, $\delta^{13} \mathrm{C}$ and $\Delta^{14} \mathrm{C}$. Therefore, it seems that the filter poresize has no effect on DOC concentration, bulk scale descriptors and DOM composition determined by optical properties. However, to our knowledge, no study has yet investigated the potential effect of filter pore-size on the analysis of the DOM molecular composition using THM-GC-MS. 
In contrast with the above bulk descriptors and DOM optical properties, molecular tools allow one to target specific compounds, often representing only a very small proportion of the total DOM and whose removal or non-removal during filtration could profoundly change the measured molecular composition of DOM. Moreover, because of this low proportion, some of these molecular compounds could be also more sensitive to filter contamination than bulk DOM descriptors. As suggested by McDowell (2003), the use of molecular tool to investigate DOM is increasingly used to develop detailed characterization of DOM constituents as for investigation of DOM composition at the seasonal and event scales (Jeanneau et al., 2014, 2015) or in different ecosystems (Frazier et al., 2003). For all these reasons, it is important to ensure that the potential effect of filter pore-size and filter composition had essentially no effect on the DOM molecular composition.

Given that filter type and porosity can introduce a bias in molecular DOM characterization, this may affect the comparability between studies that used different filtration parameters. Considering this problem, our study investigated two different filtrations using different filter types (cellulose acetate and glass fiber) and porosity $(0.2 \mu \mathrm{m}$ and 0.7 $\mu \mathrm{m})$. DOM was quantitatively characterized by the DOC concentration and qualitatively by spectroscopic and isotopic bulk-scale descriptors (specific UV absorbance at 254 and $280 \mathrm{~nm}$ and $\delta^{13} \mathrm{C}$ ). The molecular composition was investigated by thermally assisted hydrolysis and methylation (THM) with tetramethylammonium hydroxide (TMAH) coupled to gas chromatography (GC) and mass spectrometry (MS).

\section{Material and methods}

\subsection{Sampling and sample preparation}


Samples were collected in the Kervidy-Naizin catchment (Fig. 1). This $4.9 \mathrm{~km}^{2}$ lowland catchment is located in central Brittany, western France. It belongs to the French Environmental Research Observatory (ORE) AgrHyS that is the place of a long-term monitoring research program aimed at understanding the impact of agricultural intensification and climate change on hydrologic processes and water quality. This catchment benefits from a well-known hydrologic and biogeochemical context and has already been the subject of numerous investigations of the sources and dynamics of both soil and stream DOM (Morel et al., 2009; Lambert et al., 2011, 2013, 2014; Aubert et al., 2013; Jeanneau et al., 2014, 2015).

The samples were collected during hydrological year 2013/2014 from October to December 2013 at different locations on the catchment. The dataset is composed of stream waters and soil solutions to cover the soil-river continuum. Stream waters were sampled manually at four distinct locations and stored in $1 \mathrm{~L}$ glass bottles. Soil solutions were collected at three distinct locations in the catchment: (i) Kerolland transect; upslope, midslope and downslope; from 15 to $100 \mathrm{~cm}$ depth (ii) Gueriniec transect; upslope and downslope; from 15 to $50 \mathrm{~cm}$ depth (iii) Mercy wetland; from 10 to $55 \mathrm{~cm}$ depth (Supplementary Table S1). A pumping system applied to zero-tension lysimeters and piezometers allowed us to collect soil solutions which were stored in $1 \mathrm{~L}$ glass bottles and transported to the laboratory in the dark before filtration within $24 \mathrm{~h}$ after sampling. Since samples were highly concentrated in suspended matter, a first filtration was performed using $0.7 \mu \mathrm{m}$ glass fiber filters (Sartorius, Germany). Then, an aliquot of the filtrate was further filtered using $0.2 \mu \mathrm{m}$ cellulose acetate filter (Sartorius, Germany). Both fractions came from the same sample. Since $0.2 \mu \mathrm{m}$ filters are made of cellulose acetate, they were rinsed with $0.5 \mathrm{~L}$ of ultrapure water to prevent any release of carbon. This volume was previously determined to reach analytical blank values for DOC measurements. 
Additionally, soil solutions and stream waters were collected once a week during hydrological year 2013/2014 for a long-time monitoring program. The samples collected from October to December 2013 have been used to calculate background levels of DOC and UV measurements in order to identify outliers.

\subsection{Analytical methods}

Specific UV absorbance at $254 \mathrm{~nm}, 280 \mathrm{~nm}$ and DOC concentration were investigated on a dataset composed of 42 samples (17 soil solutions and 25 stream waters). The number of samples used to compare the molecular and isotopic compositions was constrained by the amount of matter necessary to perform these analyses (1.5 $\mathrm{mg}$ of organic carbon) and the available volume. Molecular and isotopic analyses were performed on 18 samples (4 soil solutions and 14 stream waters) (Supplementary Table S1).

\subsubsection{DOC concentration and $U V$-visible spectroscopic data}

DOC concentrations were determined using a Shimadzu TOC-5050A total carbon analyser. Ultra-violet absorbance measurements were performed at the two commonly investigated wavelengths: $254 \mathrm{~nm}$ and $280 \mathrm{~nm}$ (Weishaar et al., 2003; Scheel et al., 2008; Bu et al., 2010). These absorbance values $\left(\mathrm{Abs}_{254} ; \mathrm{Abs}_{280}\right)$ are used to calculate Specific UV absorbance (SUVA), which corresponds to the UV absorbance of a water sample at a given wavelength normalized for DOC concentration, denoted hereafter as $\mathrm{SUVA}_{254}$ or $\mathrm{SUVA}_{280}$ and expressed in $\mathrm{L} / \mathrm{mgCm}$. The precision of DOC and SUVA measurements is estimated to be $< \pm 5 \%$ based on the repeated analyses of sample and standard solutions. 


\subsubsection{Isotopic data}

Carbon isotopic analyses $\left(\delta^{13}\right)$ were performed at the Stable Isotope Laboratory of the PEGASE Join Research Unit of the INRA in Saint-Gilles, France, on sample solutions first acidified with $1 \mathrm{~mL} / \mathrm{L}$ of $1 \mathrm{~N} \mathrm{HCl}$ to remove dissolved inorganic carbon and then freeze-dried. Carbon isotopic measurements were determined using an elemental analyser (EA-CE 1500 NA, Carlo Erba) interfaced with an isotope ratio mass spectrometer (VG Isoprime). The $\delta^{13} \mathrm{C}$ values correspond to the relative variation between the measured ${ }^{13} \mathrm{C} /{ }^{12} \mathrm{C}$ ratio and the ${ }^{13} \mathrm{C} /{ }^{12} \mathrm{C}$ ratio of the internal standard Vienna Pee Dee Belemnite (PDB).

\subsubsection{Molecular data}

For molecular analyses, samples were prepared as follows. Approximately $2 \mathrm{mg}$ of lyophilisate and $10 \mathrm{mg}$ of tetramethylammonium hydroxide (TMAH) are introduced in a reactor and placed in a vertical microfurnace pyrolyser PZ-2020D (Frontier Laboratories). To allow TMAH reaction, pyrolysis was made at $400{ }^{\circ} \mathrm{C}$ for $1 \mathrm{~min}$. Gases produced were injected directly into a GC-2010 (Shimadzu, Japan) equipped with an SLB 5MS capillarity column (60 m, $0.25 \mathrm{~mm}$ i.d., $0.25 \mu \mathrm{m}$ film thickness) with a split mode (set between 10 and 15). The temperature of the transfer line was $321^{\circ} \mathrm{C}$, and the temperature of the injection port was 310

${ }^{\circ} \mathrm{C}$. The oven temperature started at $50{ }^{\circ} \mathrm{C}$ (held during $2 \mathrm{~min}$ ) and rose to $150{ }^{\circ} \mathrm{C}$ at 15 ${ }^{\circ} \mathrm{C} / \mathrm{min}$, then from $150{ }^{\circ} \mathrm{C}$ to $310{ }^{\circ} \mathrm{C}$ (held for $14 \mathrm{~min}$ ) at $3{ }^{\circ} \mathrm{C} / \mathrm{min}$. Helium was used as carrier gas with a flow rate of $1.0 \mathrm{~mL} / \mathrm{min}$. After separation by GC, compounds were detected by a mass spectrometer QP2010+MS (Shimadzu, Japan) operating in the full-scan mode from $\mathrm{m} / \mathrm{z}$ 50 to $\mathrm{m} / \mathrm{z}, 600$. The transfer line was set at $280{ }^{\circ} \mathrm{C}$ and molecules were ionized by electron impact using an energy of $70 \mathrm{eV}$, and an ionization source temperature set at $200{ }^{\circ} \mathrm{C}$. 
Molecules were identified by comparison of their full-scan mass spectra with the National Institute of Sciences and Technology (NIST) library and published papers (Nierop and Verstraten, 2004; Grasset et al., 2009).

The target molecular compounds in this study were lignin markers (LIG), fatty acids (FA) and carbohydrates markers (CAR). Qualitative measurements were performed using the appropriate $\mathrm{m} / \mathrm{z}$ for each compound and by integrating and correcting peak area by a mass spectra factor (MSF) (Supplementary Table S2) which correspond to the reciprocal of the proportion of the fragment used for integration and the entire fragmentogram of the NIST library. Using THM-GC-MS implies that it is necessary to assume that ionization efficiency is independent from matrix effects for all analysed compounds.

Three samples were analysed in triplicate to quantify the reproducibility of the analysis. The mean relative standard deviation express in percentage (\%RSD) based on these three analyses were calculated for each molecular parameter. The global uncertainty is $\pm 20 \%$ and corresponds to the mean of the \%RSD obtained for each molecular parameter.

Semi-quantitative analyses were performed by adding $10 \mu \mathrm{L}$ of a solution of hydrocinnamic acid d9 (Sigma-Aldrich) in methanol $(25 \mu \mathrm{g} / \mathrm{mL})$. This molecule was used as an internal standard for LIG thank to its similar chemical structure. Using MSF corrected areas of internal standard and assuming similar analytical efficiency for all target compounds, an approximation of the concentrations of the analysed markers was proposed. Since the chemical structure of CAR and FA are different from the internal standard, their concentrations must be considered as rough estimations.

\subsection{Data treatment and statistical analyses}


In this study, parameters usually used in molecular analyses were investigated to test if different pore-sizes and filter types can result in shifts in the molecular fingerprints of soil and stream DOM. Lignin markers (LIG) are classified in three main groups: vanillic (V) units (vanillic acid, vanillaldehyde and acetovanillone), syringic (S) units (syringic acid, syringaldehyde and acetosyringeone) and coumaric (C) units (coumaric acid and ferulic acid). Their relative proportions were investigated using the ratio of coumaric to vanillic units $(\mathrm{C} / \mathrm{V})$, and of syringic to vanillic units $(\mathrm{S} / \mathrm{V})$ which can be used to determine plant sources (Hedges and Mann, 1979) or lignin degradation state (Kögel, 1986). Among the fatty acids (FA) detected with THM-GC-MS, some are from microbial inputs $\left(\mathrm{C}_{13: 0} ; \mathrm{C}_{14: 0}\right.$; iso and anteiso $\mathrm{C}_{15: 0} ; \mathrm{C}_{15: 0} ;$ br $\mathrm{C}_{16: 0} ; \mathrm{C}_{16: 1}$; iso and anteiso $\left.\mathrm{C}_{17: 0} ; \mathrm{C}_{18: 1}\right)$. FA with more than $19 \mathrm{C}$ atoms are mainly plant-derived (Matsuda and Koyama, 1977; Frostegard et al., 1993), while $\mathrm{C}_{16: 0}$ and $\mathrm{C}_{18: 0}$ can derived from both microbial and plant origins (Jeanneau et al., 2014). Using this procedure, the percentage of microbial fatty acids $\left(\% \mathrm{FA}_{\text {mic }}\right)$ was estimated (Jeanneau et al., 2015) and can be used as an indicator of microbial activity. Three pairs of permethylated deoxy aldonic acids were produced during the THM of polysaccharides and free monosaccharides (Fabbri and Helleur, 1999), and those CAR were classified into three main classes: pentose (C5), hexose (C6) and deoxyhexoses (deoxyC6). For the samples analysed in this study, deoxyhexoses could not be analysed due to contamination of samples by the bactericide used during the industrial process for manufacturing aluminium trays used for the freeze-drying step. The CAR distribution was investigated using the C6/C5 ratio which is used as an indicator for microbial or plant origin (Rumpel and Dignac, 2006). Relative percentages of each molecular classes (\%LIG; \%FA; \%CAR) were measured by dividing the sum of the MSF-corrected peak area of the compounds in this class by the sum of peak area of all the classes. 
Potential outliers were identified using the box plot representation performed using XLSTAT 2013 (Addinsoft). Samples were considered as potential outliers if they are out of the interval defied by $[\mathrm{Q} 1-2 *(\mathrm{Q} 3-\mathrm{Q} 1)$; $\mathrm{Q} 3+2 *(\mathrm{Q} 3-\mathrm{Q} 1)]$ where $\mathrm{Q} 1$ is the value of the first quartile and Q3 is the value of the third quartile. If potential outliers were detected, values obtained for $<0.2 \mu \mathrm{m}$ and $<0.7 \mu \mathrm{m}$ fractions were compared to the weekly sampling dataset when this extended dataset could be used. When comparison to the weekly dataset allowed us to confirm the presence of an outlier, this sample was removed to perform the next statistical analysis.

Statistical analyses were performed using the software R 2.15.3 (R Core Team). Given that paired differences followed normal distributions (significant level at 0.05), the difference between the two filtration modes was tested by performing a paired t-test with a confident level of $95 \%$. Firstly, differences between values measured on samples filtered at 0.2 and 0.7 $\mu \mathrm{m}$ were determined. Then, if the $95 \%$ confident interval defined around the mean of the differences contain 0 , the two datasets were not considered as statistically different. This is quantified by the $p$-value which indicates no significant differences between the two filtration modes if $>0.05$.

\section{Results}

3.1. Bulk DOM descriptors (DOC, SUVA, $\delta^{13} C$ )

Among the 42 analyzed samples (17 soil solutions and 25 stream waters), the concentrations of DOC ranged from 2.2 to 44.4 and 1.6 to $15.7 \mathrm{mg} / \mathrm{L}$ in soil solutions and stream waters respectively (Table 1). The mean of the differences was $-0.39 \mathrm{mg} / \mathrm{L}$ (Fig. 2A). Four samples (number 3, 4, 12 and 13, Supplementary Table S1) were identified as potential 
outliers by the box plot representation. By comparison with the weekly sampling dataset from October to December 2013, only sample 12 is confirmed to be an outlier as the concentration of the $<0.7 \mu \mathrm{m}$ fraction $(13.4 \mathrm{mg} / \mathrm{L})$ was greatly higher than the concentration usually observed (2.1 to $4.2 \mathrm{mg} / \mathrm{L})$, probably due to analytical bias. Consequently, this sample was removed from the dataset for the next statistical analysis. The $p$-value of the paired t-test was $>0.05$ (Table 1) indicating no significant differences between the two filter types.

In the present study, $\mathrm{SUVA}_{254}$ ranged from 1.7 to $5.2 \mathrm{~L} / \mathrm{mgCm}$ and 2.4 to $5.0 \mathrm{~L} / \mathrm{mgCm}$ for soil solutions and stream waters, respectively (Table 1). The mean of the differences was 0.07 L/mgCm (Fig. 2B). SUVA 280 ranged from 1.3 to $4.3 \mathrm{~L} / \mathrm{mgCm}$ and 1.8 to $4.1 \mathrm{~L} / \mathrm{mgCm}$ for soil solutions and stream waters, respectively (Table 1). The mean of the differences was $0.05 \mathrm{~L} / \mathrm{mgCm}$ (Fig. 2C). One sample (number 30, Supplementary Table S1) for SUVA 254 and two samples (numbers 30 and 39, Supplementary Table S1) for SUVA 280 were identified as potential outliers by the box plot representation. By comparison with the weekly sampling dataset from October to December 2013, sample number 30 for $\mathrm{SUVA}_{254}$ and both sample numbers 30 and 39 for SUVA 280 were confirmed to be outliers as values measured for the < $0.7 \mu \mathrm{m}$ fractions were higher than the values usually measured, probably due to analytical bias. Consequently, these samples were removed from the dataset for the next statistical analysis. The $p$-values of the paired t-tests performed for $\mathrm{SUVA}_{254}$ and $\mathrm{SUVA}_{280}$ were $>0.05$ (Table 1) indicating no significant differences between the two filter types.

Values of carbon isotopic data $\left(\delta^{13} \mathrm{C}\right)$ ranged from -29.2 to $-26.7 \%$ o (Table 1$)$. The mean of the differences was $0.04 \%$ (Fig. $2 \mathrm{D}$ ). No outliers were identified in the dataset. The p-value of the paired t-test (Table 1) indicates no significant differences between the two filter types.

\subsection{Molecular data}


The molecular composition of DOM was investigated for 18 samples (4 soil solutions and 14 stream waters) by THM-GC-MS. The identified compounds were classified by their chemical structure into three classes: LIG, FA and CAR. Their relative proportions among the identified compounds were investigated for the two filtration processes.

$\% \mathrm{LIG}, \% \mathrm{FA}$ and $\% \mathrm{CAR}$ ranged from 19 to $62 \%$, from 26 to $76 \%$ and from 5 to $21 \%$ respectively (Table 1). The means of the differences were $2.2 \%,-1.7 \%$ and $-0.8 \%$ for $\%$ LIG, $\%$ FA and \%CAR respectively (Fig. 3). One sample (number 34, Supplementary Table S1) was identified as a potential outlier by the box plot representation for $\%$ FA. Weekly sampling dataset cannot be used to determine its outlier status since this sampling point was not investigated for its molecular composition in the long-term monitoring program. Consequently, this point was preserved for the next statistical analysis. The $p$-values of the paired t-tests (Table 1) indicate no significant differences between the two filter types.

In the present dataset, LIG were characterized by $\mathrm{C} / \mathrm{V}$ values ranging from 0.03 to 0.12 for soil DOM and from 0.08 to 0.73 for stream DOM (Table 1) and the mean of the differences was -0.02 (Fig. 4A). S/V ranged from 0.30 to 0.37 for soil DOM and from 0.39 to 0.66 for stream DOM (Table 1) and the mean of the differences was -0.02 (Fig. 4B). Two samples (numbers 35 and 36, Supplementary Table S1) for C/V and one sample (number 35, Supplementary Table S1) for S/V were identified as potential outliers by box plot representation. These samples are stream waters sampled at the outlet during a storm event. As these particular conditions are known to impact both $\mathrm{C} / \mathrm{V}$ and $\mathrm{S} / \mathrm{V}$ ratios (Dalzell et al., 2005; Hernes et al., 2008; Jeanneau et al., 2015), it was not possible to compare these values to those recorded for the weekly sampling dataset. Consequently, these samples were preserved for the next statistical analysis. The $p$-values of the paired t-tests (Table 1) indicate no significant differences between the two filter types. 
Values of LIG concentrations ranged from 0.7 to $2.4 \mathrm{mg} / \mathrm{gDOC}$ for soil solutions and from 0.3 to $4.3 \mathrm{mg} / \mathrm{gDOC}$ for stream waters (Table 1 ). The mean of the differences was 0.15 $\mathrm{mg} / \mathrm{gDOC}$ (Fig. 4C). No outliers were identified in the dataset. The $p$-value of the paired t-test (Table 1) indicate no significant differences between the two filter types.

The proportion of microbial FA calculated in this study (\%FAmic) ranged from $90 \%$ to $96 \%$ for soil solutions and from $81 \%$ to $95 \%$ for stream waters (Table 1). The mean of the differences was $1.9 \%$ (Fig. 5A). No outliers were identified in the dataset. The $p$-value of the paired t-test (Table 1) indicate no significant differences between the two filter types.

Concentration estimations for FA ranged from 0.8 to $3.3 \mathrm{mg} / \mathrm{gDOC}$ for soil solutions and from 0.7 to $9.0 \mathrm{mg} / \mathrm{gDOC}$ for stream waters (Table 1 ). The mean of the differences was $0.5 \mathrm{mg} / \mathrm{gDOC}$ (Fig. 5B). Two samples (numbers 36 and 42, Supplementary Table S1) were identified as potential outliers by the box plot representation. By comparison with the sampling dataset from October to December 2013, sample 36 was not confirmed to be an outlier, and this dataset cannot be used to confirm the outlier status of sample 42.

Consequently, these two samples were preserved for the next statistical analysis. The $p$-value of the paired t-test (Table 1) indicate no significant differences between the two filter types.

Two carbohydrates classes were identified in the present samples: C5 (pentoses) and C6 (hexoses). The C6/C5 ratio values ranged from 0.5 to 1.1 for soil solutions and from 0.5 to 2.4 for stream waters (Table 1). The mean of the differences was -0.1 (Fig. 6A). No outliers were identified in the dataset. The $p$-value of the paired t-test (Table 1) indicate no significant differences between the two filter types.

The THM-GC-MS technique used in this study allowed to measure only the terminal monosaccharides of the polysaccharides chains, and free monosaccharides. As a consequence, the carbohydrates semi-quantification performed in this study is only an estimation of these specific monosaccharides. Soil solution samples are characterized by concentrations ranging 
from 0.2 to $0.7 \mathrm{mg} / \mathrm{gDOC}$, and concentration of stream water samples range from 0.1 to 3.0 $\mathrm{mg} / \mathrm{gDOC}$ (Table 1). The mean of the differences was $0.2 \mathrm{mg} / \mathrm{gDOC}$ (Fig. 6B). One sample (number 42, Supplementary Table S1) was identified as a potential outlier by the box plot representation. This sample was a stream water sampled in Kerolland river. The weekly sampling dataset cannot be used to determine outliers since this sampling point was not investigated for its molecular composition in the long-term monitoring program. Consequently, this point was preserved for the next statistical analysis. The $p$-value of the paired t-test (Table 1) indicate no significant differences between the two filter types.

\section{Discussion}

\subsection{Is there a filter effect on bulk-scale descriptors?}

The question of the influence of filter type and pore-size on bulk-scale descriptors have been previously investigated for DOC concentration (Zsolnay, 2003; Gandois et al., 2010), and spectroscopic (Nimptsch et al., 2014) and isotopic parameters (Sanderman et al., 2008). These studies reached the same conclusion of no significant effect, or significant but small filtration effect. This point was also investigated in the present study to confirm these observations before analyzing DOM at the molecular scale. The range of values obtained for these parameters are in accordance with values previously measured in soil and stream waters for the studied catchment (Morel et al., 2009; Lambert et al., 2011, 2013, 2014; Jeanneau et al., 2014, 2015) and similar catchments worldwide (Sanderman et al., 2008).

Results on bulk-scale descriptors show no significant effect of the pore-size or composition of filters, with the exception of one sample for DOC concentration and two samples for SUVA values (Fig. 2). However, these samples were not the same for DOC and 
SUVA measurements. Moreover, by comparison with data from the same sites and sampled during the same hydrological period those points were defined as outliers. Consequently, the absence of a filtration effect on bulk-scale descriptors allowed us to investigate the potential filtration effect on DOM molecular analysis by THM-GC-MS.

\subsection{Is there a filter effect on molecular composition?}

Present-day challenges in DOM biogeochemistry include a better understanding of their sources and sinks (Nguyen and Hur, 2011). The development of molecular tools to probe the composition of DOM allows the determination of thousands of individual formulae by FT-ICR-MS (Koch et al., 2005) or the identification of individual compounds implied in natural macromolecules such as lignins, carbohydrates and fatty acids by THM-GC-MS (Challinor, 2001). Those analyses lead to a mine of information. However, since those compounds are at trace levels, the use of molecular tools requires more attention to potential contamination. It is necessary to determine the absence of filtration effects to allow the comparison of different studies.

In the present study, the distribution of 43 target compounds was investigated through the relative proportion of three classes of compounds (LIG, FA and CAR) and molecular ratios. As revealed by the paired t-tests, filter type and porosity had no significant effect on the distribution of the three classes of compounds and molecular ratios analyzed in this study.

Pseudo-quantitative analysis was performed by the addition of hydrocinnamic acid $\mathrm{d} 9$ as an internal standard allowing the estimation of the concentration of each individual compound. In order to test the potential effect of filter type and porosity on this pseudoquantitative analysis, the concentration of the three classes of compounds (LIG, FA, CAR) was investigated. For those three classes, the mean of the differences are slightly higher than 
0 (Fig. 4A, 5B, 6B), which implies that concentrations measured on samples filtered at $0.2 \mu \mathrm{m}$ were higher than those measured in the same sample filtered at $0.7 \mu \mathrm{m}$. Since $0.2 \mu \mathrm{m}$ filters are made of organic material, a hypothesis to explain those differences could be the contamination of the samples by the filters. However, $0.2 \mu \mathrm{m}$ filters are made of cellulose acetate, and cellulose is a polymer of glucose (i.e. a hexose). Such a contamination would increase: (i) the concentration of CAR, (ii) the C6/C5 ratio and (iii) the \%CAR. However, higher concentrations in the $<0.2 \mu \mathrm{m}$ fraction were also recorded for LIG and FA. No significant variations of the $\mathrm{C} 6 / \mathrm{C} 5$ ratio were recorded (Fig. 5A), and the distributions between \%LIG, \%FA and \%CAR (Fig. 3) were not affected by the different filtration modes. Moreover, the samples that present the most important differences between the two filtration modes were not the same for each quantitative parameter. All these observations allow us to invalidate the hypothesis of a contamination by cellulose acetate filters rinsed with $500 \mathrm{~mL}$ of ultrapure water.

A second hypothesis that could explain the difference in terms of concentration between the two filtration modes could be an analytical bias due to the sorption of organic molecules on mineral surfaces. This interaction between organic matter and mineral surfaces, called the shield effect, is known to impact the analytical efficiency of lignin phenols by the alkaline $\mathrm{CuO}$ oxidation (Hernes et al., 2013). In samples filtered at $0.2 \mu \mathrm{m}$, a larger fraction of the mineral phases was removed compared to samples filtered at $0.7 \mu \mathrm{m}$. Thus, the ratio OM to mineral phases increased, which could induce a slightly higher analytical efficiency.

The use of filters with different composition or porosity does not significantly affect the distribution of the different target molecules analyzed by THM-GC-MS, and only slightly impact the estimation of their concentrations. As a consequence, it seems reasonable to prefer the use of $0.7 \mu \mathrm{m}$ glass fiber filters to prevent any contamination. Moreover, the realization of one single filtration step at $0.7 \mu \mathrm{m}$ instead of two successive filtration steps allows one to 
reduce analytical cost and environmental impact due to the saving of $500 \mathrm{~mL}$ of ultrapure water required to pre-wash $0.2 \mu \mathrm{m}$ filters.

\subsection{A gap in the POM-DOM continuum?}

In the POM-DOM continuum (Verdugo et al., 2004), the transition between POM and DOM was operationally defined at $0.45 \mu \mathrm{m}$. At this cutoff threshold, OM is implied to be present as colloids. According to this idea of a continuum, there should be a decrease in DOC concentrations between the $<0.7 \mu \mathrm{m}$ and the $<0.2 \mu \mathrm{m}$ fractions. However, no significant differences were observed for DOC concentrations (Fig. 2A), which is commonly described (Zsolnay, 2003; Sanderman et al., 2008). Two hypothesis could be considered: (i) the absence of colloids between 0.2 and $0.7 \mu \mathrm{m}$ or (ii) the absence of $\mathrm{OM}$ in the colloids occurring in this size range. Filella and Buffle (1993) or Atteia and Kozel (1997) report that colloids have been identified in this range in surface waters (river, lake) and groundwaters by different analytical techniques. Moreover, in this present study, the coloration of $0.2 \mu \mathrm{m}$ filters after the filtration step suggested the retention of material larger than $0.2 \mu \mathrm{m}$ (data not shown). As a consequence, the colloids retained by the $0.2 \mu \mathrm{m}$ filters did not contain OM, which would represent a gap in the POM-DOM continuum between 0.7 and $0.2 \mu \mathrm{m}$. How can this apparent gap be explained?

This apparent lack of OM between 0.2 and $0.7 \mu \mathrm{m}$ could be due to the nature and dynamics of supramolecular associations building up colloids. Colloids are composed of a combination of inorganic matter (e.g., metal oxyhydroxides, clays, calcium carbonates) and organic matter (e.g., lignins, tannins, fatty acids, polysaccharides, proteins etc) (Gaillardet et al., 2003) bound together by weak interactions (Kleber and Johnson, 2010). Colloids are characterized by high specific surface areas and a strong sorption capacity, which made them 
highly reactive (Stumm, 1993). Their size distributions depend on the nature of the sample, and could change over time, especially after sampling, when samples are transferred from an open and natural system to a closed one (e.g., sampling bottles) (Buffle and Leppard, 1995). The smallest particles coagulate to form larger ones and the largest settle down, resulting in a narrowing of the distribution of colloids (Filella and Buffle, 1993). However the cohesive forces that build up larger colloids can easily be broken by manual shaking (Esfahani et al., 2015). During the filtration process, the behaviour of weakly aggregating colloids depends on the equilibrium between cohesive and disruptive forces (Wolthers, 1996) and especially shear forces (Tolpekin et al., 2004). The shear forces occurring during the normal filtration at 0.2 $\mu \mathrm{m}$ may have resulted in the breakup of colloids. Then during the second filtration step, colloids $<0.2 \mu \mathrm{m}$ passed through the filter, while colloids $>0.2 \mu \mathrm{m}$ were broken up by shear forces and passed through the filter. The retentate was composed of mineral matter $>0.2 \mu \mathrm{m}$. As a consequence, $\mathrm{OM}$ may occur in the fraction between 0.2 and $0.7 \mu \mathrm{m}$, but apparently in colloids whose cohesive forces are not strong enough to resist the normal filtration process. Tangential filtration, by decreasing shear forces, could minimize the breakup of colloids and could be more appropriate to investigate the fate of OM along the POM-DOM continuum.

\section{Conclusions}

The potential impact of two different filter types (cellulose acetate or glass fiber) and filter pore-size $(0.2 \mu \mathrm{m}$ or $0.7 \mu \mathrm{m})$ used for DOM extraction have been studied for stream waters and soil solution samples. As found in previous studies, the choice of filter has no significant effect on qualitative and quantitative bulk-scale descriptors along the soil-river continuum. 
Since looking at the molecular composition of DOM may be very fruitful for biogeochemical and ecological studies, and since DOM compounds are more vulnerable to potential contamination, it was necessary to ensure that the molecular composition of DOM was not affected by the filter type and filter porosity used for the filtration step.

Molecular characterization by THM-GC-MS highlights no significant filtration effect on the distribution of the 43 target compounds that cover the investigation of polysaccharides, fatty acids, lignins and tannins in DOM. Results of pseudo-quantification of the three classes of compounds (LIG, FA and CAR) highlight higher concentrations for samples filtered at 0.2 $\mu \mathrm{m}$ compared to $0.7 \mu \mathrm{m}$, which were attributed to an analytical bias due to the sorption of organic molecules on mineral surfaces, resulting in a shield effect during the thermochemolysis step. Then it seems more efficient to perform one single filtration step, using $0.7 \mu \mathrm{m}$ glass fiber filters allowing the reduction of analytical cost and environmental impact.

From a conceptual point of view, this apparent similarity between $<0.7$ and $<0.2 \mu \mathrm{m}$ DOM, interpreted in the framework of the POM-DOM continuum would signify a lack of DOM between those two thresholds. Considering the colloidal forms of DOM at this size range, built up by weak forces, this apparent lack of DOM has been interpreted as the result of the breakup of colloids caused by shear forces applied during filtration.

\section{Acknowledgments}

This research was supported by the French National Research Agency through the MOSAIC project and the French Ministry of Scientific Research. The long-term monitoring program on the Kervidy-Naizin watershed is supported by the ORE AgrHyS. We thank all the technical staff from Géosciences Rennes and INRA who helped with field and laboratory work. 


\section{Associate Editor-Ingrid Kögel-Knabner}

\section{References}

Ågren, A., Buffam, I., Jansson, M., Laudon, H., 2007. Importance of seasonality and small streams for the landscape regulation of dissolved organic carbon export. Journal of Geophysical Research 112. DOI: 10.1029/2006JG000381

Atteia, O., Kozel, R., 1997. Particle size distributions in waters from a karstic aquifer: from particles to colloids. Journal of Hydrology 201, 102-119.

Aubert, A.H., Gascuel-Odoux, C., Gruau, G., Akkal, N., Faucheux, M., Fauvel, Y., Grimaldi, C., Hamon, Y., Jaffrézic, A., Lecoz-Boutnik, M., Molénat, J., Petitjean, P., Ruiz, L., Merot, P., 2013. Solute transport dynamics in small, shallow groundwater-dominated agricultural catchments: insights from a high-frequency, multisolute $10 \mathrm{yr}$-long monitoring study. Hydrology and Earth System Sciences 17, 1379-1391.

Bu, X., Wang, L., Ma, W., Yu, X., McDowell, W.H., Ruan, H., 2010. Spectroscopic characterization of hot-water extractable organic matter from soils under four different vegetation types along an elevation gradient in the Wuyi Mountains. Geoderma 159, $139-146$.

Buffle, J., Leppard, G.G., 1995. Characterization of aquatic colloids and macromolecules. 1. Structure and behavior of colloidal material. Environmental Science \& Technology 29, 2169-2175.

Challinor, J.M., 2001. Review: the development and applications of thermally assisted hydrolysis and methylation reactions. Journal of Analytical and Applied Pyrolysis 61, $3-34$. 
Dalzell, B.J., Filley, T.R., Harbor, J.M., 2005. Flood pulse influences on terrestrial organic matter export from an agricultural watershed. Journal of Geophysical Research 110. DOI: $10.1029 / 2005 J G 000043$

Esfahani, M.R., Stretz, H.A., Wells, M.J.M., 2015. Abiotic reversible self-assembly of fulvic and humic acid aggregates in low electrolytic conductivity solutions by dynamic light scattering and zeta potential investigation. Science of The Total Environment 537, 8192.

Fabbri, D., Helleur, R., 1999. Characterization of the tetramethylammonium hydroxide thermochemolysis products of carbohydrates. Journal of Analytical and Applied Pyrolysis 49, 277-293.

Filella, M., Buffle, J., 1993. Factors controlling the stability of submicron colloids in natural waters. Journal of Colloids and Surfaces 73, 255-273.

Frazier, S.W., Nowack, K.O., Goins, K.M., Cannon, F.S., Kaplan, L.A., Hatcher, P.G., 2003. Characterization of organic matter from natural waters using tetramethylammonium hydroxide thermochemolysis GC-MS. Journal of Analytical and Applied Pyrolysis 70, 99-128.

Frostegard, A., Tunlid, A., Baath, E., 1993. Phospholipid fatty acid composition, biomass, and activity of microbial communities from two soil types experimentally exposed to different heavy metals. Applied and Environmental Microbiology 59, 3605-3617.

Gaillardet, J., Viers, J., Dupré, B., 2003. Trace elements in river waters. In: Treatise on Geochemistry. Elsevier, pp. 225-272.

Gandois, L., Tipping, E., Dumat, C., Probst, A., 2010. Canopy influence on trace metal atmospheric inputs on forest ecosystems: Speciation in throughfall. Atmospheric Environment 44, 824-833. 
Grasset, L., Rovira, P., Amblès, A., 2009. TMAH-preparative thermochemolysis for the characterization of organic matter in densimetric fractions of a Mediterranean forest soil. Journal of Analytical and Applied Pyrolysis 85, 435-441.

Gu, B., Schmitt, J., Chen, Z., Liang, L., McCarthy, J.F., 1994. Adsorption and desorption of natural organic matter on iron oxide: mechanisms and models. Environmental Science \& Technology 28, 38-46.

Hedges, J.I., Mann, D.C., 1979. The characterization of plant tissues by their lignin oxidation products. Geochimica et Cosmochimica Acta 43, 1803-1807.

Hernes, P.J., Kaiser, K., Dyda, R.Y., Cerli, C., 2013. Molecular trickery in soil organic matter: hidden lignin. Environmental Science \& Technology 47, 9077-9085.

Hernes, P.J., Spencer, R.G.M., Dyda, R.Y., Pellerin, B.A., Bachand, P.A.M., Bergamaschi, B.A., 2008. The role of hydrologic regimes on dissolved organic carbon composition in an agricultural watershed. Geochimica et Cosmochimica Acta 72, 5266-5277.

Jeanneau, L., Denis, M., Pierson-Wickmann, A.-C., Gruau, G., Lambert, T., Petitjean, P., 2015. Sources of dissolved organic matter during storm and inter-storm conditions in a lowland headwater catchment: constraints from high-frequency molecular data. Biogeosciences 12, 4333-4343.

Jeanneau, L., Jaffrezic, A., Pierson-Wickmann, A.-C., Gruau, G., Lambert, T., Petitjean, P., 2014. Constraints on the sources and production mechanisms of dissolved organic matter in soils from molecular biomarkers. Vadose Zone Journal 13, 1-9.

Kalbitz, K., Solinger, S., Park, J.-H., Michalzik, B., Matzner, E., 2000. Controls on the dynamics of dissolved organic matter in soils: a review. Soil Science 165, 277-304.

Kleber, M., Johnson, M.G., 2010. Advances in Understanding the Molecular Structure of Soil Organic Matter. In: Advances in Agronomy. Elsevier, pp. 77-142. 
Koch, B.P., Witt, M., Engbrodt, R., Dittmar, T., Kattner, G., 2005. Molecular formulae of marine and terrigenous dissolved organic matter detected by electrospray ionization Fourier transform ion cyclotron resonance mass spectrometry. Geochimica et Cosmochimica Acta 69, 3299-3308.

Kögel, I., 1986. Estimation and decomposition pattern of the lignin component in forest humus layer. Soil Biology and Biochemistry 18, 589-594.

Krieg, N.R., 2005. Procaryotic domains. In: Bergey’s Manual of Systematic Bacteriology. Springer, pp. 21-26.

Lambert, T., Pierson-Wickmann, A.-C., Gruau, G., Jaffrezic, A., Petitjean, P., Thibault, J.N., Jeanneau, L., 2014. DOC sources and DOC transport pathways in a small headwater catchment as revealed by carbon isotope fluctuation during storm events.

Biogeosciences 11, 3043-3056.

Lambert, T., Pierson-Wickmann, A.-C., Gruau, G., Jaffrezic, A., Petitjean, P., Thibault, J.-N., Jeanneau, L., 2013. Hydrologically driven seasonal changes in the sources and production mechanisms of dissolved organic carbon in a small lowland catchment: Seasonal changes in DOC dynamics. Water Resources Research 49, 5792-5803.

Lambert, T., Pierson-Wickmann, A.-C., Gruau, G., Thibault, J.-N., Jaffrezic, A., 2011. Carbon isotopes as tracers of dissolved organic carbon sources and water pathways in headwater catchments. Journal of Hydrology 402, 228-238.

Matsuda, H., Koyama, K., 1977. Early diagenesis of fatty acids in lacustrine sediments: II. A statistical approach to changes in fatty acid composition from recent sediments and some source materials. Geochimica et Cosmochimica Acta 41, 1825-1834.

McDowell, W.H., 2003. Dissolved organic matter in soils-future directions and unanswered questions. Geoderma 113, 179-186. 
Morel, B., Durand, P., Jaffrezic, A., Gruau, G., Molenat, J., 2009. Sources of dissolved organic carbon during stormflow in a headwater agricultural catchment. Hydrological Processes 23, 2888-2901.

Neale, P.A., Antony, A., Gernjak, W., Leslie, G., Escher, B.I., 2011. Natural versus wastewater derived dissolved organic carbon: Implications for the environmental fate of organic micropollutants. Water Research 45, 4227-4237.

Nguyen, H.V.-M., Hur, J., 2011. Tracing the sources of refractory dissolved organic matter in a large artificial lake using multiple analytical tools. Chemosphere 85, 782-789.

Nierop, K.G.J., Verstraten, J.M., 2004. Rapid molecular assessment of the bioturbation extent in sandy soil horizons under pine using ester-bound lipids by on-line thermally assisted hydrolysis and methylation-gas chromatography/mass spectrometry. Rapid Communications in Mass Spectrometry 18, 1081-1088.

Nimptsch, J., Woelfl, S., Kronvang, B., Giesecke, R., González, H.E., Caputo, L., Gelbrecht, J., von Tuempling, W., Graeber, D., 2014. Does filter type and pore size influence spectroscopic analysis of freshwater chromophoric DOM composition? Limnologica Ecology and Management of Inland Waters 48, 57-64.

Rumpel, C., Dignac, M.-F., 2006. Gas chromatographic analysis of monosaccharides in a forest soil profile: Analysis by gas chromatography after trifluoroacetic acid hydrolysis and reduction-acetylation. Soil Biology and Biochemistry 38, 1478-1481.

Sanderman, J., Baldock, J.A., Amundson, R., 2008. Dissolved organic carbon chemistry and dynamics in contrasting forest and grassland soils. Biogeochemistry 89, 181-198.

Scheel, T., Haumaier, L., Ellerbrock, R.H., Rühlmann, J., Kalbitz, K., 2008. Properties of organic matter precipitated from acidic forest soil solutions. Organic Geochemistry 39, $1439-1453$. 
Stumm, W., 1993. Aquatic colloids as chemical reactants: surface structure and reactivity. Colloids and Surfaces A: Physicochemical and Engineering Aspects 73, 1-18.

Tolpekin, V.A., Duits, M.H.G., van den Ende, D., Mellema, J., 2004. Aggregation and breakup of colloidal particle aggregates in shear flow, studied with video microscopy. Langmuir 20, 2614-2627.

Verdugo, P., Alldredge, A.L., Azam, F., Kirchman, D.L., Passow, U., Santschi, P.H., 2004. The oceanic gel phase: a bridge in the DOM-POM continuum. Marine Chemistry 92, $67-85$.

Weishaar, J.L., Aiken, G.R., Bergamaschi, B.A., Fram, M.S., Fujii, R., Mopper, K., 2003. Evaluation of specific ultraviolet absorbance as an indicator of the chemical composition and reactivity of dissolved organic carbon. Environmental Science \& Technology 37, 4702-4708.

Wolthers, W., 1996. The viscosity and sedimentation of aggregating colloidal dispersions in a Couette flow. Journal of Rheology 40, 55-67.

Zsolnay, Á., 2003. Dissolved organic matter: artefacts, definitions, and functions. Geoderma $113,187-209$. 
Fig. 1: Map of the Kervidy-Naizin catchment (Brittany, France) and location of the sampling sites

Fig. 2: Graphical representation of the difference between DOM $<0.2 \mu \mathrm{m}$ and DOM $<0.7 \mu \mathrm{m}$ as a function of their mean for DOC concentration, spectroscopic and isotopic parameter, and for soil solutions (grey dots) and stream waters (black squares). For each parameter, the full line represents the mean of the differences and dashed lines define the $95 \%$ confident interval around the mean.

* indicate values defined as outliers and excluded from the dataset used to perform the paired $\mathrm{t}$-tests.

Fig. 3: Graphical representation of the difference between DOM $<0.2 \mu \mathrm{m}$ and DOM $<0.7 \mu \mathrm{m}$ as a function of their mean for \%LIG, \%FA and \%CAR, and for soil solutions (grey dots) and stream waters (black squares). For each parameter, the full line represents the mean of the differences and dashed lines define the $95 \%$ confident interval around the mean.

Fig. 4: Graphical representation of the difference between DOM $<0.2 \mu \mathrm{m}$ and DOM $<0.7 \mu \mathrm{m}$ as a function of their mean for C/V, S/V and LIG concentration, and for soil solutions (grey dots) and stream waters (black squares). For each parameter, the full line represents the mean of the differences and dashed lines define the $95 \%$ confident interval around the mean.

Fig. 5: Graphical representation of the difference between DOM $<0.2 \mu \mathrm{m}$ and DOM $<0.7 \mu \mathrm{m}$ as a function of their mean for $\% \mathrm{FA}_{\text {mic }}$ and FA concentration, and for soil solutions (grey dots) and stream waters (black squares). For each parameter, the full line represents the mean of the differences and dashed lines define the $95 \%$ confident interval around the mean.

Fig. 6: Graphical representation of the difference between DOM $<0.2 \mu \mathrm{m}$ and DOM $<0.7 \mu \mathrm{m}$ as a function of their mean for C6/C5 and CAR concentration, and for soil solutions (grey dots) and stream waters (black squares). For each parameter, the full line represents the mean of the differences and dashed lines define the $95 \%$ confident interval around the mean. 
Fig. 1

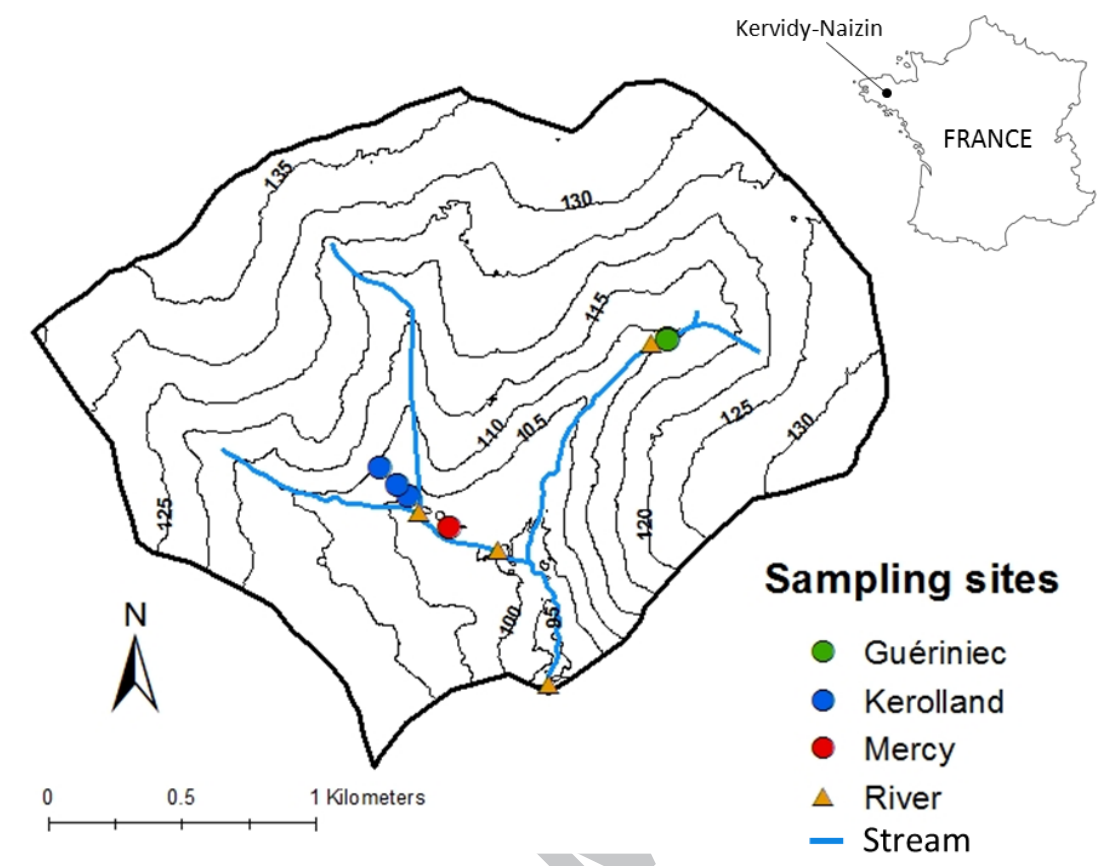


Fig. 2
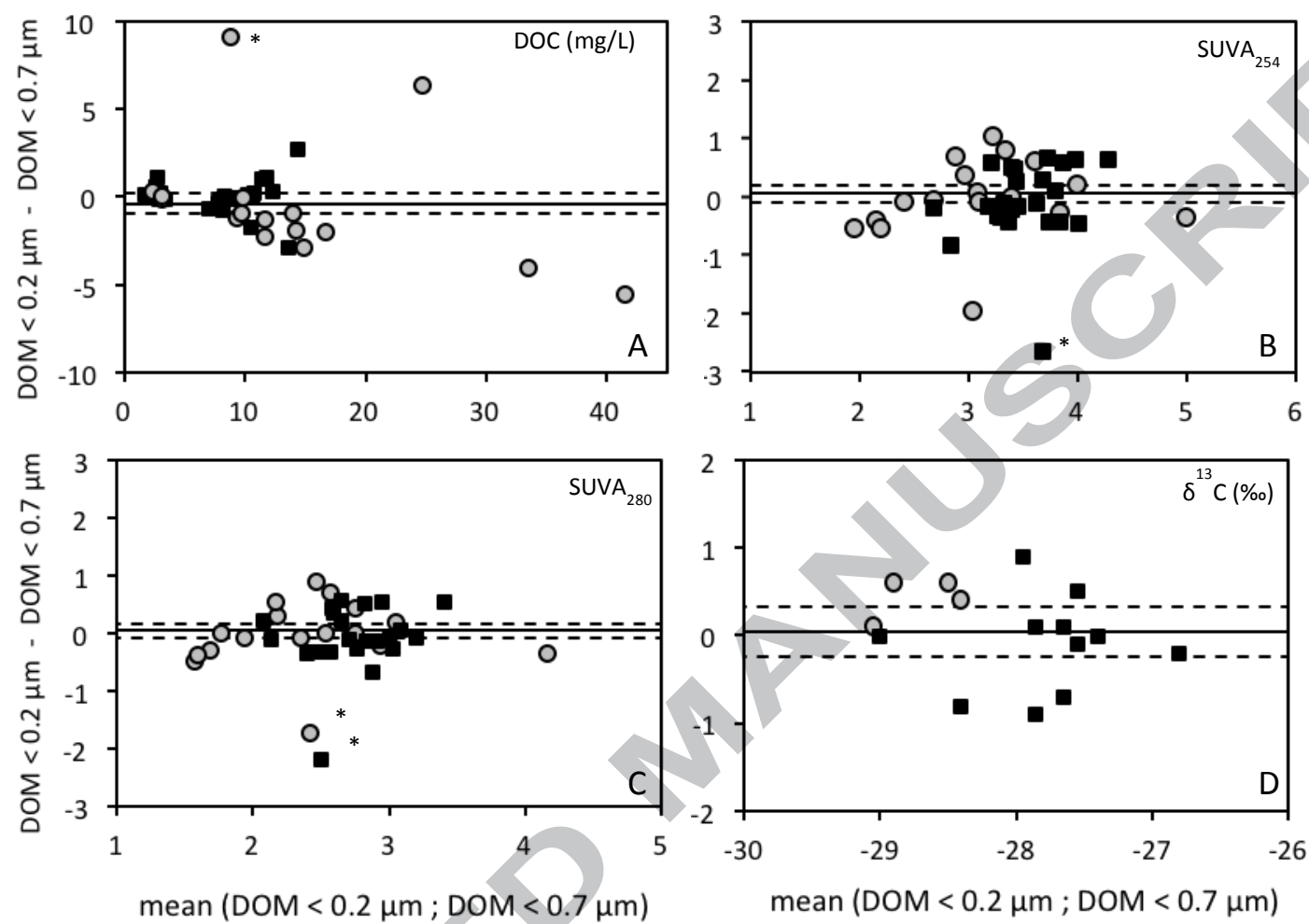
Fig. 3

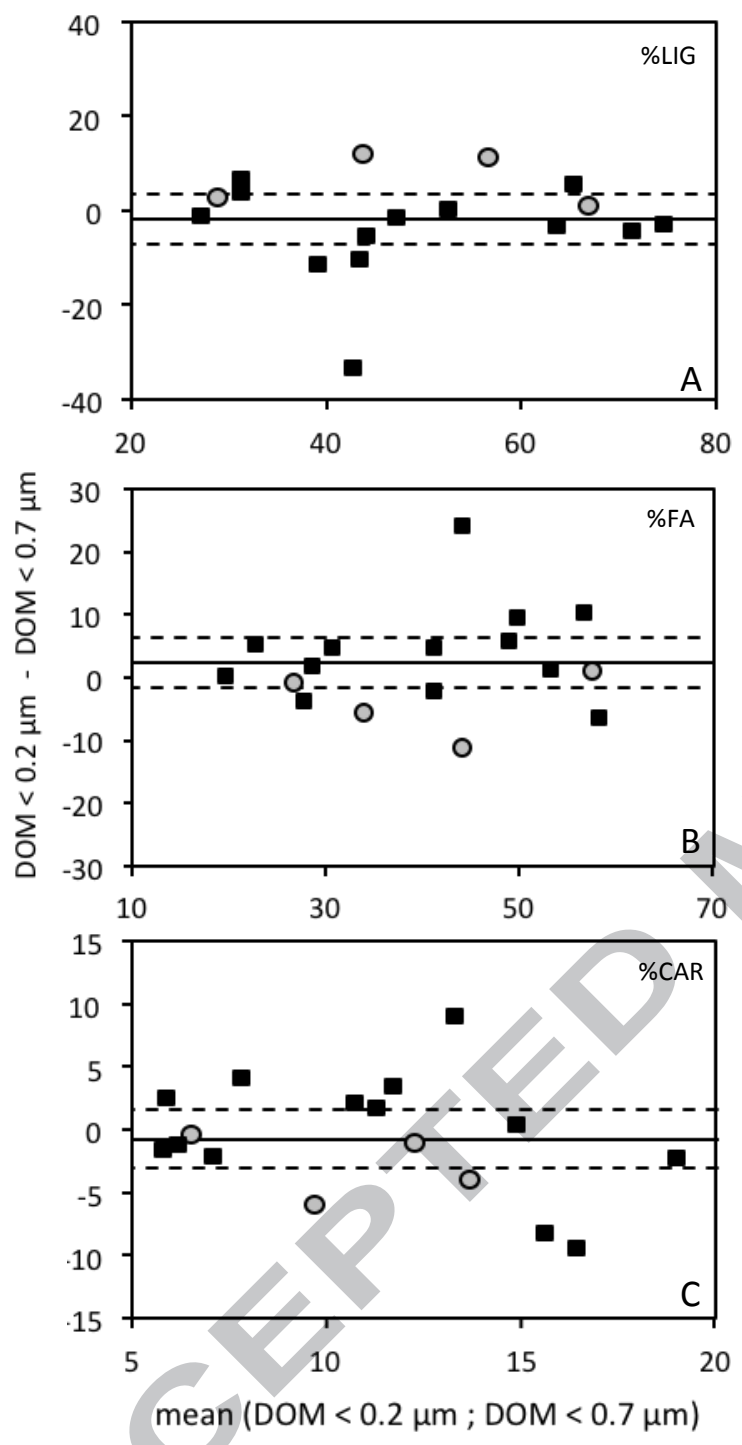


Fig.4
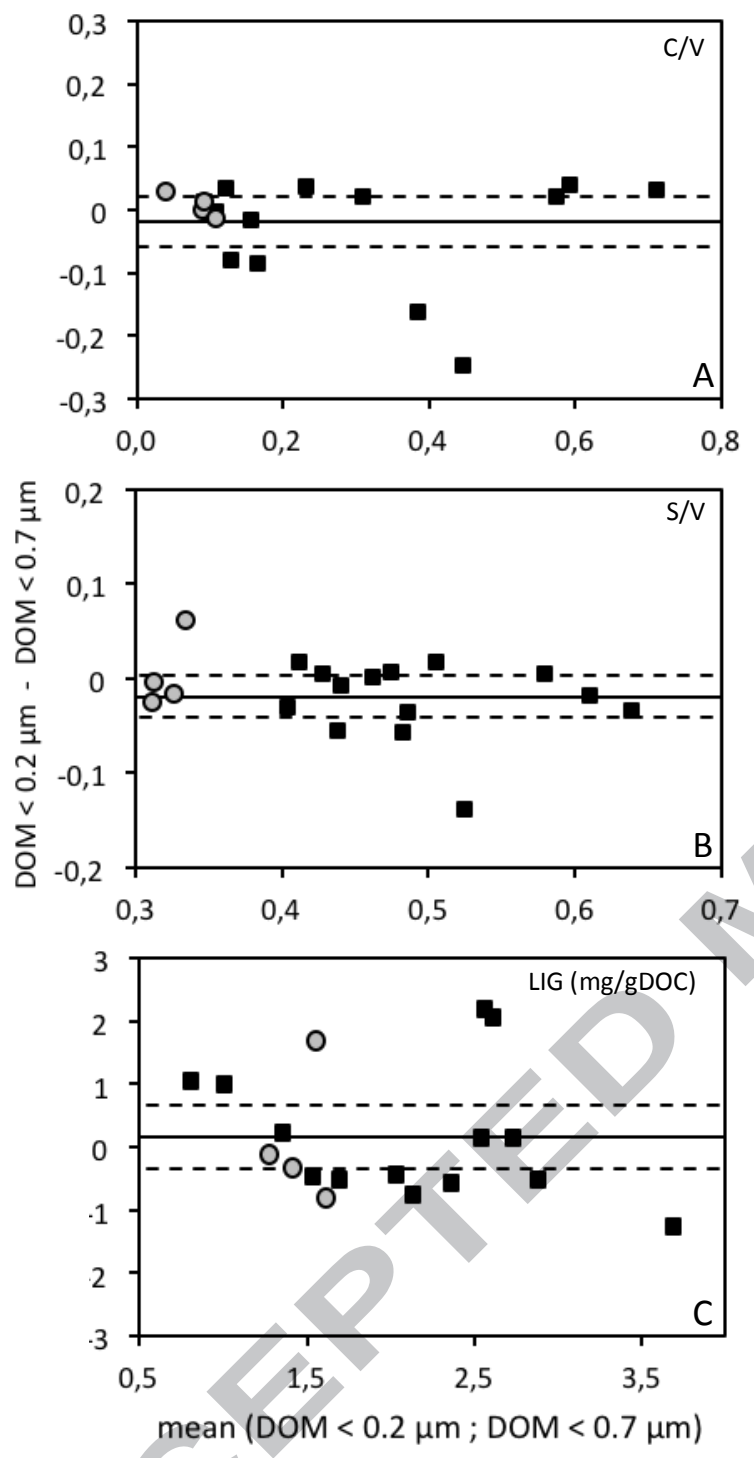
Fig. 5
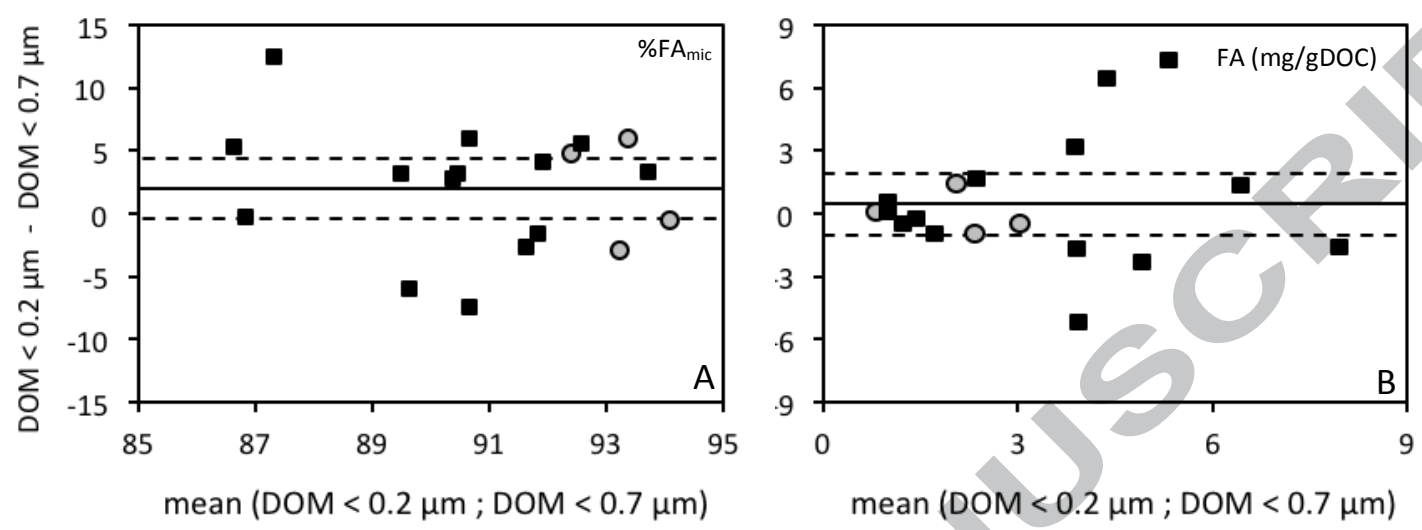
Fig. 6
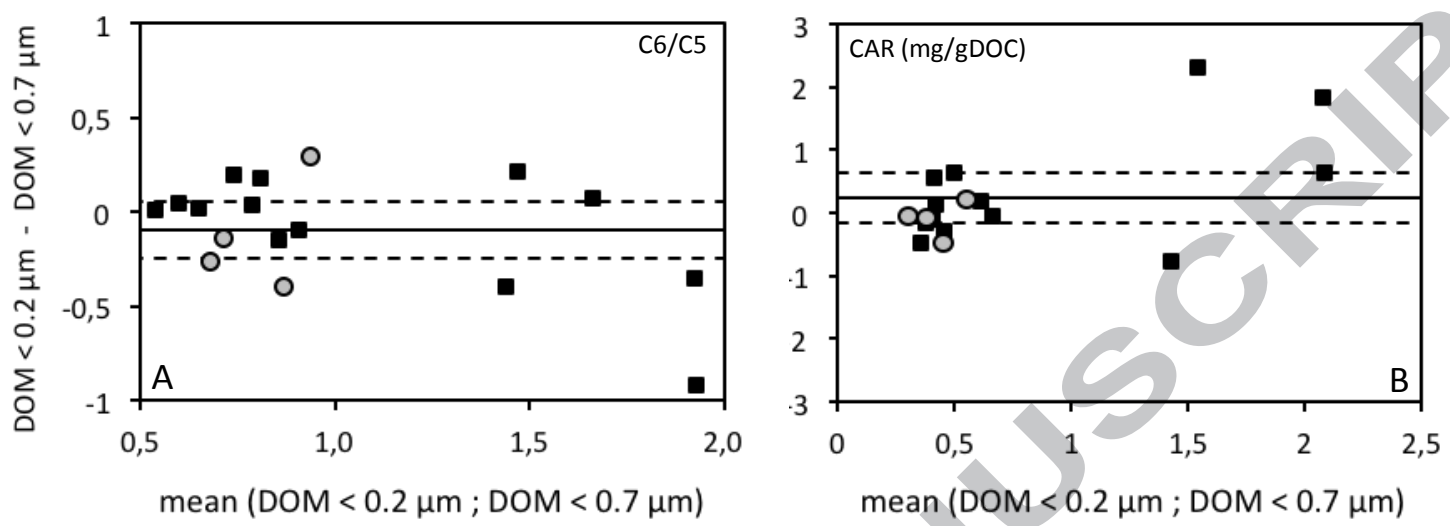
Table 1. Number of samples, minimal, maximal and mean value of the dataset for each parameter and $p$-value of the paired t-test. A $p$-value $>0.05$ indicate no significant differences.

\begin{tabular}{ccccccccc}
\hline & \multirow{2}{*}{$\begin{array}{c}\text { Number } \\
\text { Parameter }\end{array}$} & \multicolumn{2}{c}{ Minimal value } & \multicolumn{2}{c}{ Maximal value } & \multicolumn{2}{c}{ Mean } \\
\cline { 3 - 6 } & samples & $0.2 \mu \mathrm{m}$ & $0.7 \mu \mathrm{m}$ & $0.2 \mu \mathrm{m}$ & $0.7 \mu \mathrm{m}$ & $0.2 \mu \mathrm{m}$ & $0.7 \mu \mathrm{m}$ & $p$-value \\
\hline DOC (mg/L) & 41 & 1.7 & 1.6 & 38.8 & 44.4 & 10.0 & 10.4 & 0.176 \\
SUVA $_{254}$ & 40 & 1.7 & 2.2 & 4.8 & 5.2 & 3.3 & 3.4 & 0.936 \\
SUVA $_{280}$ & 39 & 1.3 & 1.8 & 4.0 & 4.3 & 2.6 & 2.6 & 0.396 \\
$\delta^{13}$ C & 15 & -29.0 & -29.2 & -26.9 & -26.7 & -28.0 & -28.1 & 0.774 \\
\%LIG & 17 & 20 & 19 & 62 & 61 & 41 & 39 & 0.271 \\
\%FA & 17 & 26 & 27 & 73 & 76 & 48 & 50 & 0.509 \\
\%CAR & 17 & 5 & 5 & 18 & 21 & 11 & 11 & 0.458 \\
C/V & 18 & 0.05 & 0.03 & 0.73 & 0.70 & 0.24 & 0.26 & 0.286 \\
S/V & 18 & 0.30 & 0.30 & 0.62 & 0.66 & 0.45 & 0.46 & 0.118 \\
LIG (mg/gDOC) & 18 & 1.2 & 0.3 & 3.7 & 4.3 & 2.1 & 1.9 & 0.539 \\
\%FA & 18 & 87 & 81 & 96 & 95 & 92 & 90 & 0.110 \\
FA (mg/gDOC) & 18 & 0.9 & 0.7 & 9.0 & 8.7 & 3.4 & 3.0 & 0.516 \\
C6/C5 & 17 & 0.5 & 0.5 & 1.7 & 2.4 & 1.0 & 1.1 & 0.197 \\
CAR (mg/gDOC) & 17 & 0.1 & 0.1 & 3.0 & 1.8 & 0.9 & 0.7 & 0.266 \\
\hline
\end{tabular}

\section{Highlights}

- Comparative study of DOM isolated using two filter types and two pore size filters

- No pore size or filter type effect was observed on bulk scale descriptors

- No filter effect was observed on the distribution of the 43 target molecules

- Possibility to compare molecular results for different filter type and porosity

- Breakup of colloids due to forces applied during filtration at $0.2 \mu \mathrm{m}$ 
Graphical abstract

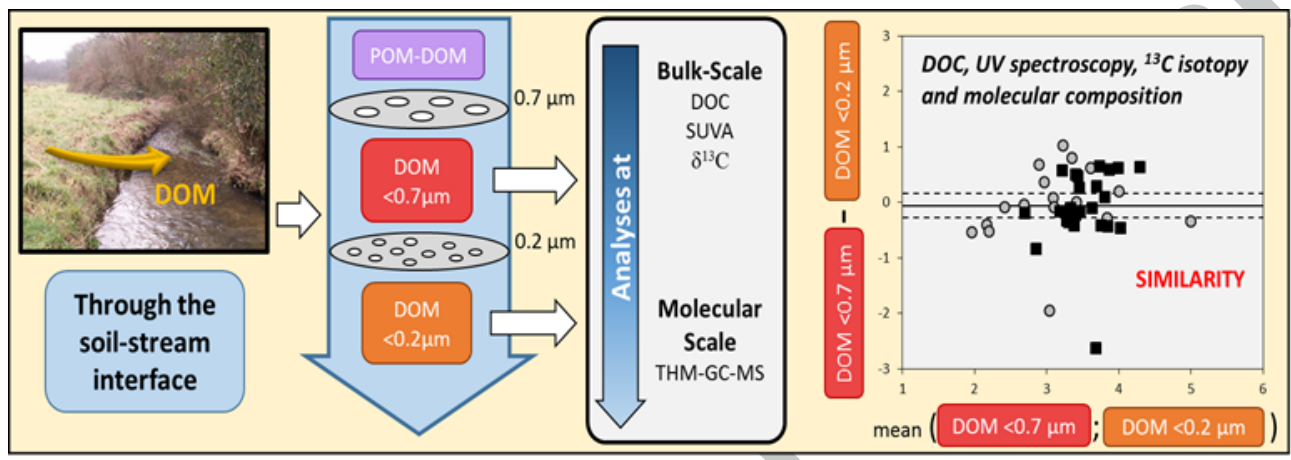

